\title{
Estimation of Copper and Molybdenum Grades and Recoveries in the Industrial Flotation Plant Using the Artificial Neural Network
}

\author{
Ebrahim Allahkarami' ${ }^{1}$ Omid Salmani Nuri' ${ }^{1}$, Aliakbar Abdollahzadeh ${ }^{1,2}$, Bahram Rezai', \\ Mostafa Chegini ${ }^{1}$ \\ ${ }^{1}$ Amirkabir University of Technology, Tehran, Iran \\ ${ }^{2}$ University of Kashan, Kashan, Iran \\ Email: ebrahim.allahkarami@yahoo.com,omidnuri@aut.ac.ir, abdzad@aut.ac.ir, rezai1@yahoo.com, \\ m chegini60@yahoo.com
}

Received 25 April 2016; accepted 25 July 2016; published 28 July 2016

Copyright (C) 2016 by authors and Scientific Research Publishing Inc.

This work is licensed under the Creative Commons Attribution International License (CC BY).

http://creativecommons.org/licenses/by/4.0/

c) (i) Open Access

\begin{abstract}
In this paper, prediction of copper and molybdenum grades and their recoveries of an industrial flotation plant are investigated using the Artificial Neural Networks (ANN) model. Process modeling has done based on 92 datasets collected at different operational conditions and feed characteristics. The prominent parameters investigated in this network were $\mathbf{p H}$, collector, frother and F-Oil concentration, size percentage of feed passing 75 microns, moisture content in feed, solid percentage, and grade of copper, molybdenum, and iron in feed. A multilayer perceptron neural network, with 10:10:10:4 structure (two hidden layers), was used to estimate metallurgical performance. To obtain the optimal hidden layers and nodes in a layer, a trial and error procedure was done. In training and testing phases, it achieved quite correlations of 0.98 and 0.93 for Copper grade, of 0.99 and 0.92 for Copper recovery, of 0.99 and 0.92 for Molybdenum grade and of 0.99 and 0.94 for Molybdenum recovery prediction, respectively. The proposed neural network model can be applied to determine the most beneficial operational conditions for the expected Copper and Molybdenum grades and their recovery in final concentration of the industrial copper flotation process.
\end{abstract}

\section{Keywords}

Prediction of Grade and Recovery, Artificial Neural Network, Copper Flotation, Copper Concentrator Plant 


\section{Introduction}

Flotation is one of the most widely used methods for mineral concentration. The separation process is a surfacechemistry based process for the separation of fine particles that is based on difference in wettability at the solid particle surfaces. Flotation is mainly used in mineral concentration, treatment of industrial wastewater and the water purification [1].

Artificial Neural Networks are successfully applied for the modeling and control of complex systems such as copper flotation [2], liquid-liquid extraction [3] and numerous fields of mineral processing [4]-[6]. Basically, ANNs are numerical structures inspired by the learning rule in the human brain. The Artificial Neural Network is a modeling method, linking the input to the target data and using a set of nonlinear basis functions. The back propagation algorithm is a method of adjusting the weighted connections between neurons to minimize the difference between predicted and observed data [7].

ANNs are based on neurons, the duties of which are to estimate complex nonlinear associates existing between ANN input and output variables [8] [9]. The ANN is an important tool for correlation between experimental data. There are different types of neural networks such as the single layer feed forward network, multilayer feed forward network, and the recurrent neural network. Among them, multilayer neural network is the most popular, which is successful in modeling and prediction problems [10].

The use of neural networks to predict the efficiency of deinking from paper by flotation was reported by Labidi et al. [11]. The results of them showed that there was a good agreement between the observed and the estimated values. They found that the proposed NN model could be accurately applied in the deinking plant modeling to determine the optimal operational conditions. Mohanty [12] designed a feed forward neural network model to control the interface level in a flotation column. This controller was satisfactorily performed for both of liquid-gas and liquid-gas-solid systems. Cilek [13] predicted locked cycle test results for several flotation circuits by using neural network. He found the neural network model as a simulation method could be applied to estimate the stage number of the flotation circuit by changing flotation variables.

Moolan et al. used an image analysis and a feed forward neural network to predict flotation recovery and grade from the froth surfaces and structures. They also predicted the effects of some froth characteristics such as froth stability, bubble size and froth structure on froth solid concentration by a neural network [14].

Massinaei and Doostmohammadi [15] used NN and statistical modeling techniques to predict the effect of superficial gas velocity, solids percentage and concentration and type of frother on the bubble surface area flux in a flotation column. They found that the proposed neural network outputs had a good agreement with the experimental data with a high correlation.

Jorjani et al. [16] used ANN to predict the solid percentage, $\mathrm{pH}$, coal particle size, collector, frother and conditioner dosage and rotation rate effect on coal flotation. The results of modeling showed that there was a good agreement between the experimental and the estimated values.

In this paper, a multilayer feed forward neural network was applied to estimate the copper and molybdenum grades and their recoveries of flotation concentrate based on operational parameters of the industrial flotation process. In this work, operational parameters were $\mathrm{pH}$, collector, frother and F-Oil concentration, size percentage of feed passing 75 microns, moisture content in the feed, solid percentage, and grade of copper, molybdenum and iron in the feed. Modeling was performed by means of a neural network, MATLAB software package.

This paper is arranged as follows. Section 2 presents the industrial flotation process. The ANN prediction model is presented in Section 3. Results and discussion are given in Section 4. Conclusions are put forth in Section 5 .

\section{Industrial Flotation Process}

The Sarcheshmeh copper ore body Located in southeast Iran that contains 1 billion tonnes averaging $0.80 \%$ copper and $0.03 \%$ molybdenum. It has been processing 40,000 t/d (old plant since 1982) and 22,000 t/d (new plant since 2002) of ore.

A simplified flow sheet of Sarcheshmeh flotation circuit is shown in Figure 1 that consists of roughing, cleaning, cleaning-scavenging and re-cleaning stages. In the concentrator plant, to produce $70 \%$ of the product finer than 75 $\mu \mathrm{m}$, output of three stages of crushing is fed to ball mills in the closed circuit with cyclones. Product of grinding stage is fed to flotation circuit. The rougher flotation bank consists of eight cells of $130 \mathrm{~m}^{3}$, the cleaner, scavenger banks each have three and five cells of $50 \mathrm{~m}^{3}$, respectively. The coarse portion of the combined rougher and 


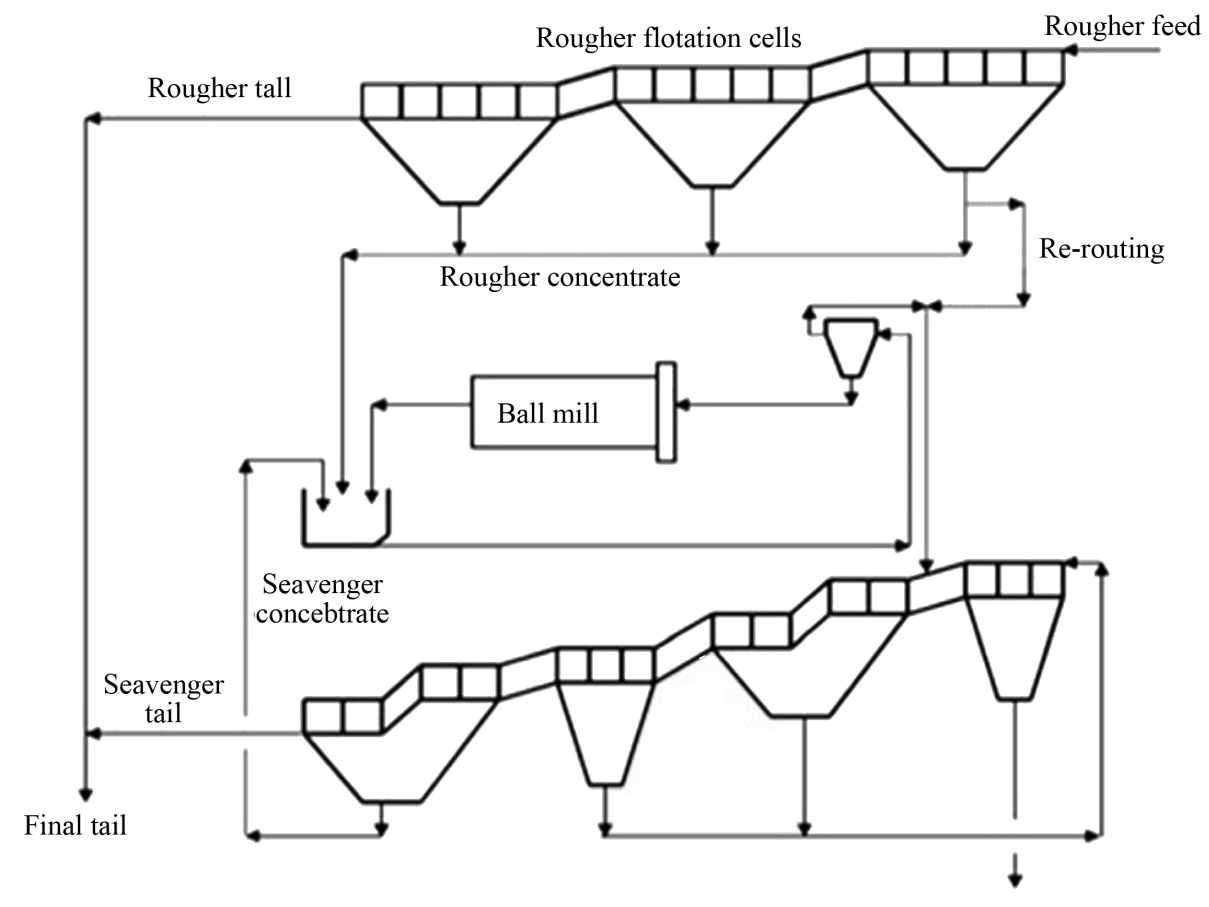

Figure 1. A simplified flow sheet of Sarcheshmeh flotation circuit [17].

scavenging concentrates (i.e. underflow of secondary cyclone) is ground by using regrind mill that is a 3.962-m by 5.791-m ball mill. The tailings of the rougher flotation are discarded to the final tails, and the concentrate is reground. The concentrate of copper was produced by the stages of flotation cleaning and re-cleaning. In this flotation circuit, reagents of sodium isopropyl xanthate and Nascol 1451 (dithiophosphate and mercaptobenzothiazol) are used as collector and reagents of methyl isobutyl carbonyl and Dow 250 (polypropylene glycol methyl ether) are used as frother.

After flotation stages, a concentrate was produced with an average grade of $28 \%$ - 30\% copper and $0.7 \%$ - $0.8 \%$ molybdenum. From the previous experience, some factors that have an important role in the flotation of copper ore were selected as the input variables [17] [18].

\section{Artificial Neural Network}

ANNs are developed on the basis of the human brain and its neural system that composed of billions of neurons which are interconnected by synapses. Similarly, an artificial neural network is made up of many processing elements that are also called neurons.

The output of each neuron is calculated with applying the weight and bias parameters and then, as the input is fed to the next layer's neurons. The output of each neuron is passed by an activation function (transfer function) [19]. As shown in Figure 2, each neuron is made up of the following: inputs, the weight parameters, a bias, a summing junction, a local induced field, a transfer function, and an output variable [19].

In the ANN, each neuron computes the net weighted input by the following equations:

$$
\begin{gathered}
u_{k}=\sum_{j=1}^{n} w_{k j} x_{j} \\
y_{k}=f\left(v_{k}\right) \rightarrow y_{k}=f\left(u_{k}+b_{k}\right)
\end{gathered}
$$

where $x_{1}, x_{2}, \ldots, x_{n}$ are the input variables; $w k_{1}, w k_{2}, \ldots, w k_{n}$ are the synaptic weights of neuron $k$; $u_{k}$ is the sums of the linear combination of each neuron; $b_{k}$ is the bias; $f(\cdot)$ is the activation function; and $y_{k}$ is the output of each neuron. The most important issue in the ANN arrangement is to determine the number of hidden layers and nodes. Usually, the optimum number of hidden layers and neurons in each layer are found by a trial and error method [20]. 
In this research, the best structure and geometry of the ANN model 10-10-10-4 (Figure 3), which adequately recognized the effects of different operational conditions and feed characteristics on the flotation process, can predict copper and molybdenum grades and their recoveries.

\section{Result and Discussion}

A back propagation feed forward neural network with two hidden layers was constructed for modeling of the industrial flotation process.

In this study, for the modeling problem, $\mathrm{pH}$, collector, frother and F-Oil concentration, size percentage of feed passing 75 microns, moisture content in feed, solid percentage, grade of copper, molybdenum and iron in feed were considered as inputs to the network. Variables of copper, molybdenum grade and recovery in the final concentrate were used as the network output. Table 1 and Table 2 present the summary statistics for each input and output variable, respectively.

Data pre-processing can be effective in the process of training the neural network [21]. To have a successful training process, totally of data were normalized and then fed to $\mathrm{NN}$ for the training phase. Finally, these data changed in the range of -1 and 1 . The normalized value $\left(X_{N}\right)$ for each raw input/output dataset was calculated using the following equation:

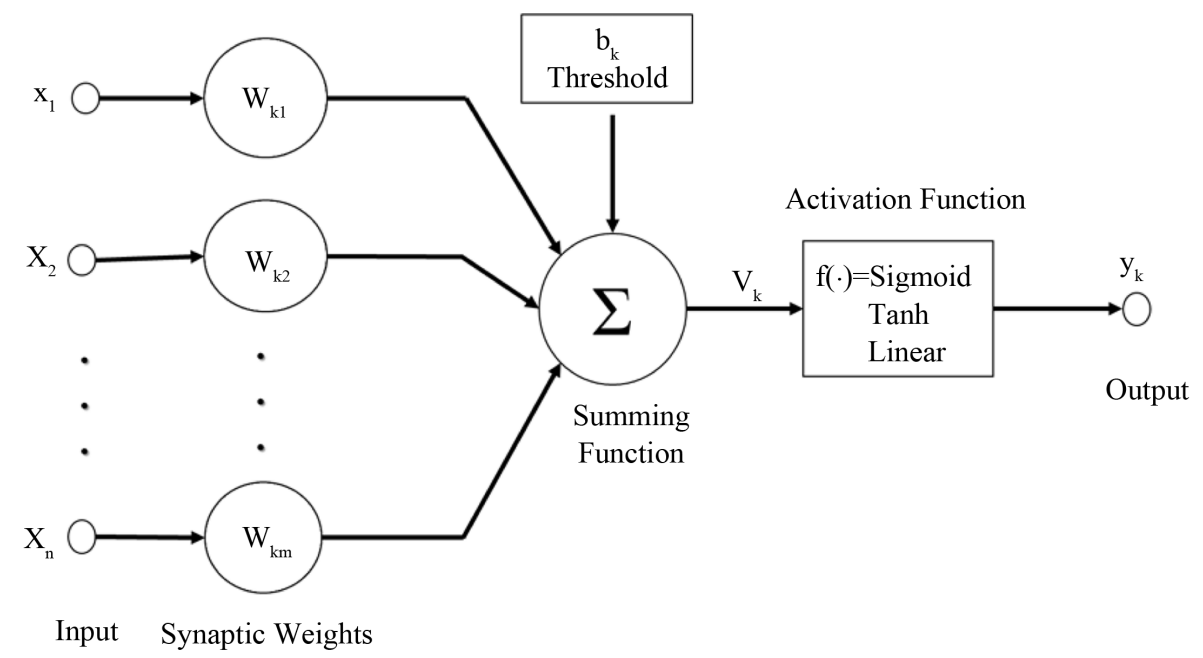

Figure 2. Single node anatomy [20].

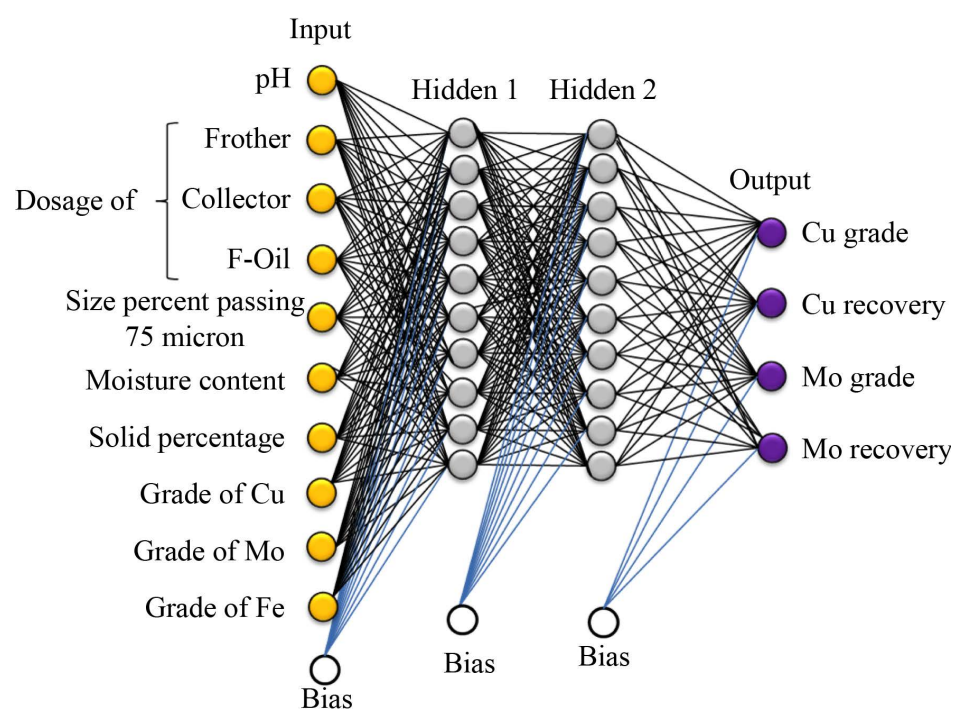

Figure 3. Architecture of ANN. 


$$
X_{N}=2 \frac{X-X_{\min }}{X_{\max }-X_{\min }}-1
$$

where $X_{N}$ is the normalized value of each input or output variable, $X$ is an original value of a variable, and $X_{\max }$ and $X_{\min }$ are maximum and minimum original values of the variables, respectively.

In this research, several networks were created, trained, and tested. The optimum number of hidden layers and nodes in each layer were determined by the trial and error procedure. A total of 92 data sets were used in the predictions by ANN; 69 and 23 data sets were applied for training and testing the network, respectively for estimation of copper and molybdenum grades and their recovery. In the present work, a feed forward back propagation with parameters shown in Table 3 was used for modeling and prediction. The term back propagation refers to the

Table 1. The summary statistics for input variables.

\begin{tabular}{ccccc}
\hline Variable & Min & Max & Mean & Standard deviation \\
\hline pH & 12.09 & 12.39 & 12.3034 & 0.0559 \\
Collector dosage (g/ton) & 10.5 & 25.0673 & 18.5813 & 2.9573 \\
Frother dosage (g/ton) & 12 & 22.5 & 16.3130 & 2.0084 \\
F-Oil dosage (g/ton) & 1 & 5.9486 & 3.3258 & 0.7240 \\
Solid percentage (\%) & 25.1106 & 29.0876 & 27.4425 & 0.8253 \\
Moisture percent (\%) & 4.4367 & 5.4665 & 4.8356 & 0.2116 \\
Size percent of feed passing 75 micron & 61.1934 & 66.7105 & 63.0652 & 0.9499 \\
Copper grade in feed (\%) & 0.5528 & 0.8221 & 0.6674 & 0.0540 \\
Molybdenum grade in feed (\%) & 0.0194 & 0.0403 & 0.0270 & 0.0036 \\
Iron grade in feed (\%) & 3.7106 & 6.5878 & 4.8260 & 0.6401 \\
\hline
\end{tabular}

Table 2. The summary statistics for output variables.

\begin{tabular}{ccccc}
\hline Variable & Min & Max & Mean & Standard deviation \\
\hline Copper grade in final concentrate (\%) & 18.6122 & 28.8488 & 24.5525 & 1.7797 \\
Copper recovery in final concentrate (\%) & 82.6762 & 90.1167 & 86.3908 & 1.8602 \\
Molybdenum grade in final concentrate (\%) & 0.4811 & 1.1309 & 0.7321 & 0.1535 \\
Molybdenum recovery in final concentrate (\%) & 47.2212 & 79.4940 & 64.3083 & 7.4264 \\
\hline
\end{tabular}

Table 3. The basic architecture and the training parameters of the ANN.

\begin{tabular}{c} 
Parameter \\
Number of layers \\
Number of neurons in input layer \\
Number of neurons in first hidden layer \\
Number of neurons in second hidden layer \\
Number of neurons in output layer \\
Transfer function of the first hidden layer \\
Transfer function of the second hidden layer \\
Transfer function of the output layer \\
Number of epochs \\
Learning rate \\
Tan sigmoid \\
Linear \\
0.1 \\
0.9 \\
\hline
\end{tabular}


process by which derivatives of the network error, with respect to network weights and biases, can be computed (Figure 4). Due to the convergence speed and the performance of the network to find a better solution, a learning rule was selected the Levenberg-Marquardt training method. Without momentum, a network may be trapped in local minima. Therefore, optimum values of 0.1 and 0.9 were selected for learning rate and momentum, respectively. However, ANN analyses were done with these values. Using this algorithm, the main ANN structure was constructed and trained. The training process was stopped after 292 epochs (Figure 5). The procedure of MSE

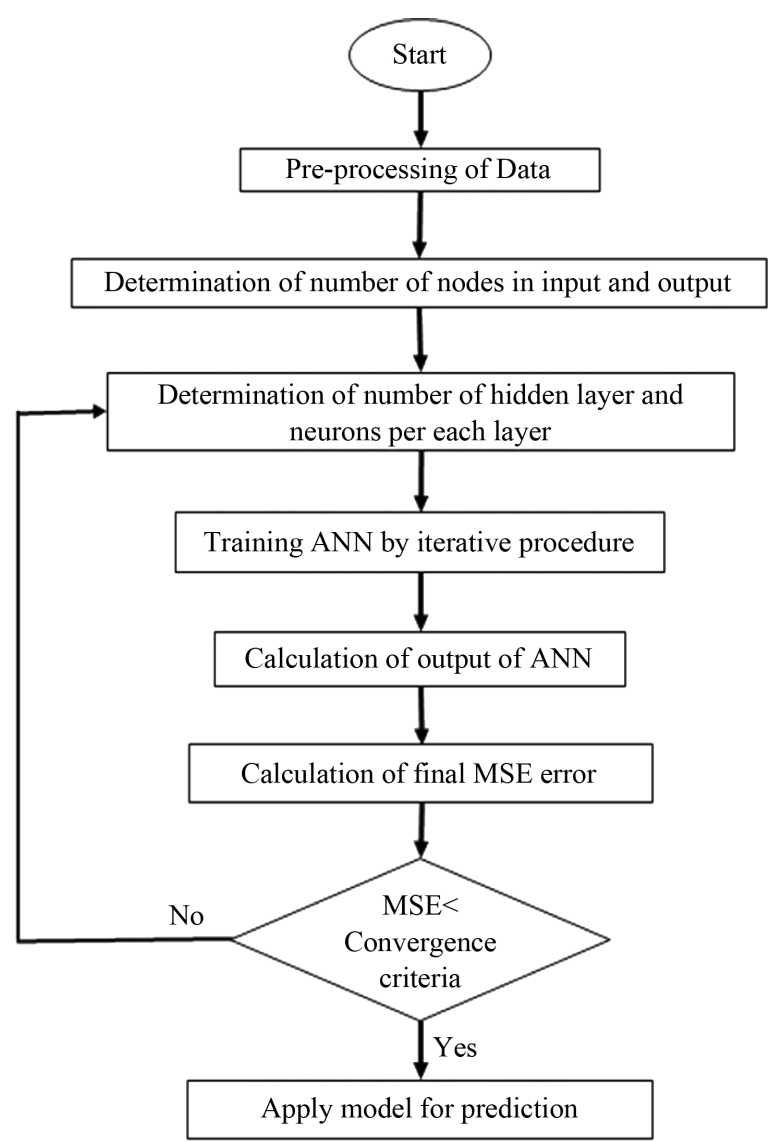

Figure 4. Algorithm of the back propagation training.

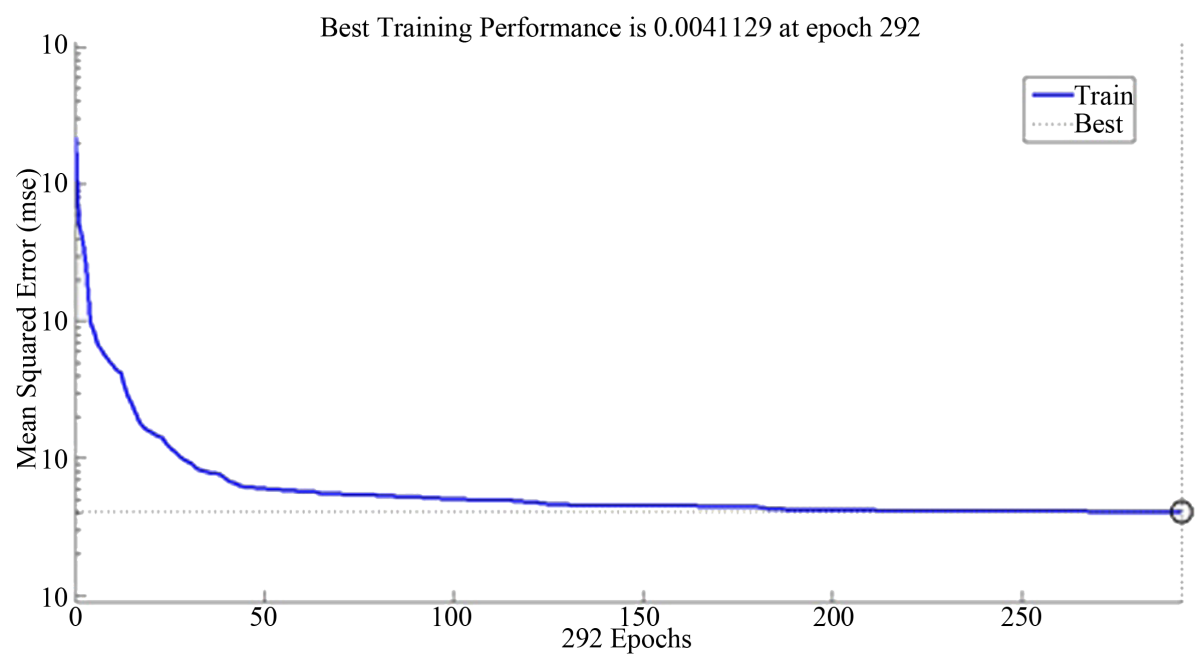

Figure 5. Curve of MSE to training subset. 
reduction with an increase of epochs is shown in Figure 5. As seen in this figure, MSE descends to lower values with increasing epoch. This method is based on the back propagation error algorithm, which is an iterative supervised learning technique. As be mentioned, the performance criteria were MSE that was the average squared error between the predicted and the observed outputs.

$$
\operatorname{MSE}=\frac{1}{n} \sum_{i=1}^{n}\left(Y_{i}-\overline{Y_{i}}\right)^{2}
$$

where $Y$ is predicted values, $\bar{Y}$ is observed values and $n$ is number of data sets.

The ANN model has been developed by considering two hidden layers in the MLP configuration and training using the back propagation algorithm. During each iteration, the error signal travels backwards through the network, starting at the output neurons and ending at the input synapses. The neural network learns the relations contained in between the input and the output variables and correlates the variables by the optimal weights that minimize the differences between the estimated and observed output values. For each iteration, an error between the predicted and the observed values is propagated backward from the output layer towards the input layer through the hidden layers. This work continued until the predicted and the target values are in a good agreement (the convergence criteria is met) [22]. The correlation coefficient (R) values in the training stages for copper, molybdenum grades and their recoveries were 0.98, 0.99 and 0.99, 0.99, respectively (Figure 6).
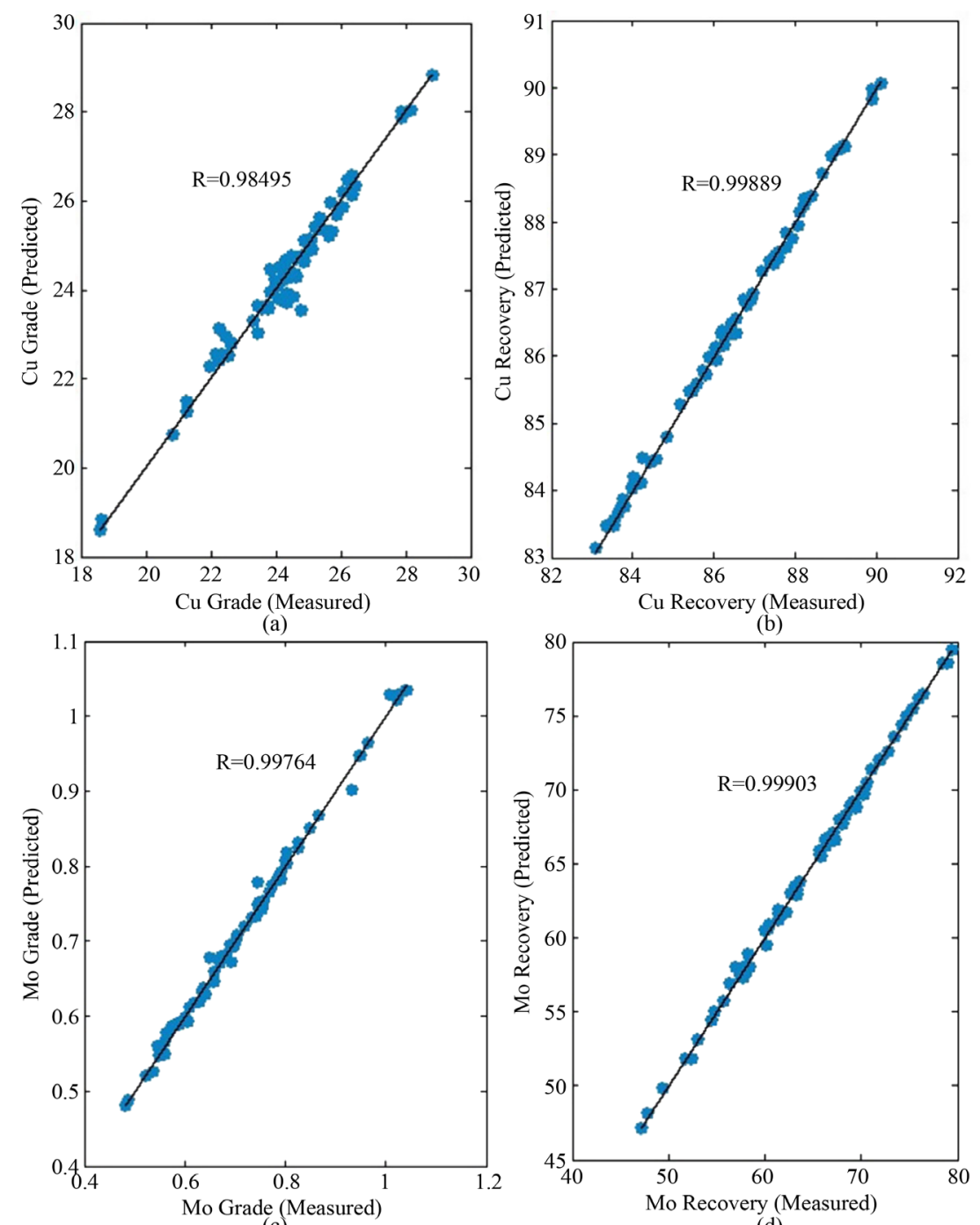

(c)

(d)

Figure 6. Correlation between estimated and observed values in the testing stage: (a) Copper grade, (b) Copper recovery, (c) Molybdenum grade and (d) Molybdenum recovery. 
When the training stage was completed, the network testing stage was begun for its generalization capability. The testing phase for its generalization ability was done by investigating its capability to estimate NN output sets that were unfamiliar data sets to the neural network. For this purpose, 29 new data sets were selected that were not included in the training stage. The testing stage shows that the model can predict copper and molybdenum grades and their recoveries quite satisfactorily. The correlation coefficient (R) values in the testing stage for copper, molybdenum grades and copper, molybdenum recoveries were $0.93,0.92$ and $0.92,0.94$ respectively (Figure 7). It was observed that copper and molybdenum grades and their recoveries in final concentrate of industrial copper flotation using the ANN model could be predicted satisfactorily. The results of agreement between measured and predicted values of output are shown in Figure 8. It is observed that simultaneous Copper and molybdenum grades and their recoveries can be estimated satisfactorily using an NN model. Apparently, it has been observed from Figure 7 as well as Figure 8 that copper and molybdenum grades and their recoveries predicted by ANN is in within a very good acceptance limit. Finally, the network is well fitted with the data collected and shows the least variation error in predicting the copper and molybdenum grades and their recoveries in testing stage.
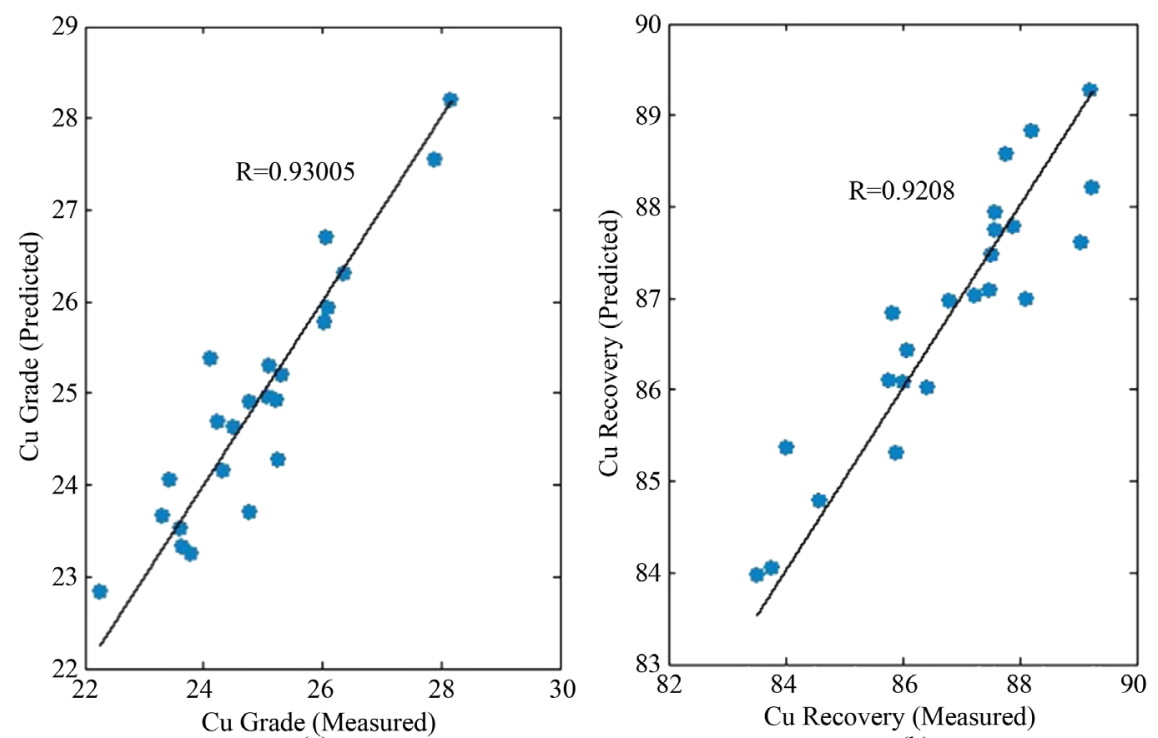

(a)

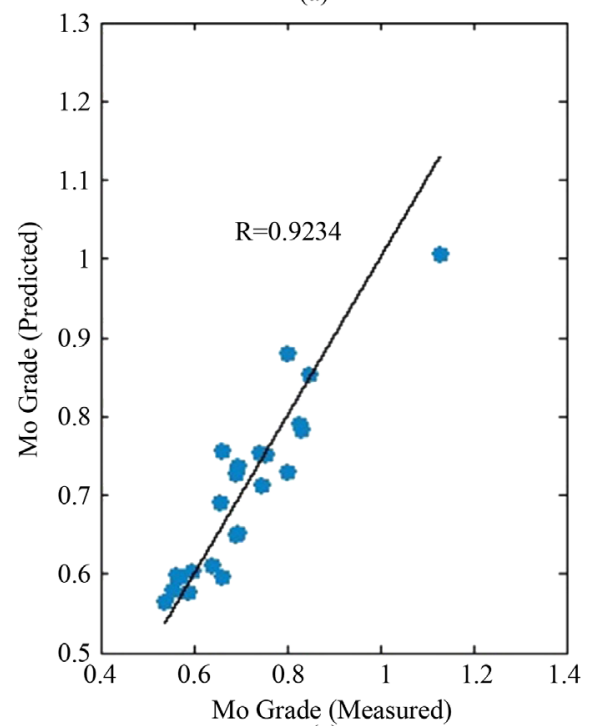

(b)

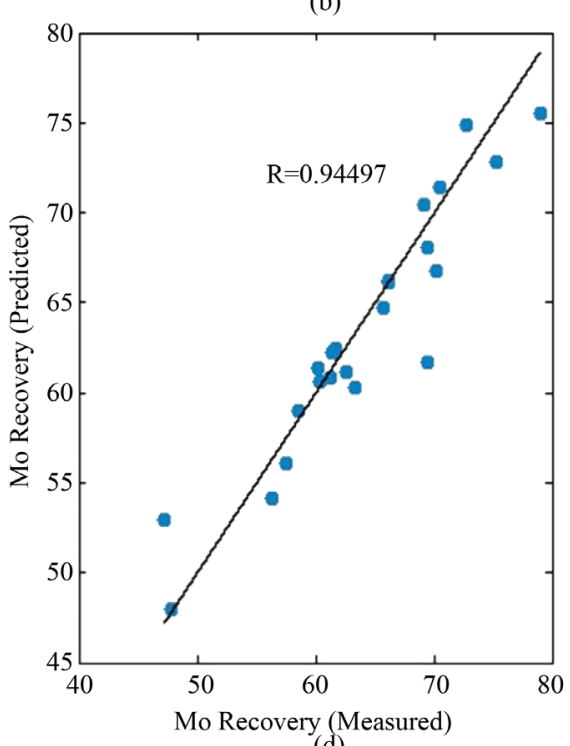

(c)

(d)

Figure 7. Correlation between estimated and observed values in the testing stage: (a) Copper grade, (b) Copper recovery, (c) Molybdenum grade and (d) Molybdenum recovery. 


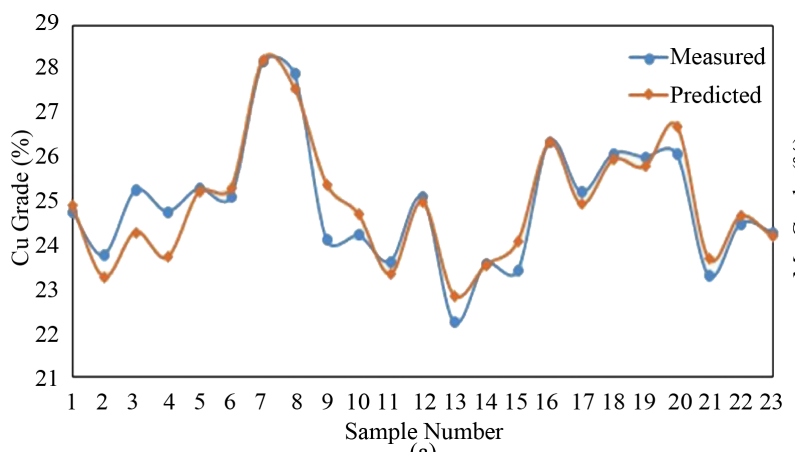

(a)

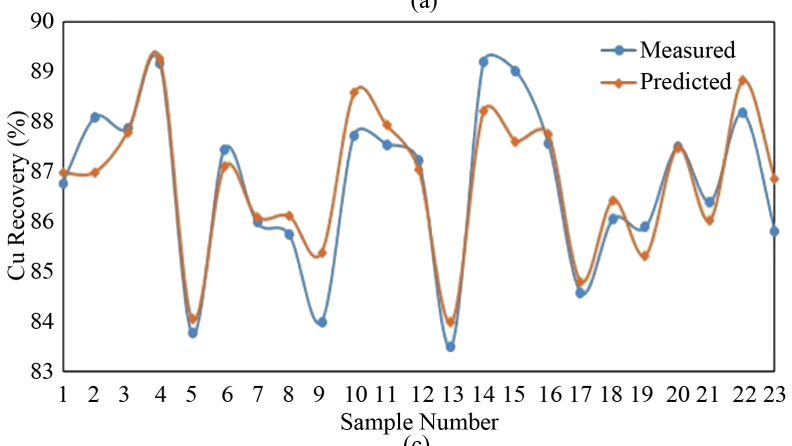

(c)

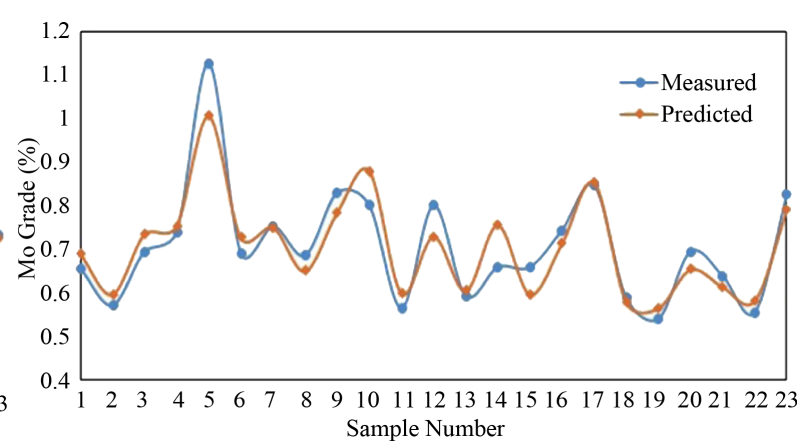

(b)

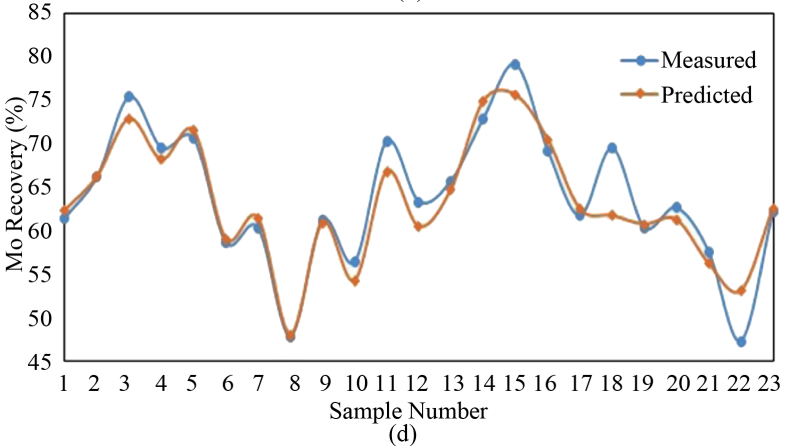

(d)

Figure 8. Comparison between predicted and measured values in the testing stage: (a) Copper grade, (b) Molybdenum grade, (c) Copper recovery and (d) Molybdenum recovery.

\section{Conclusions}

1) This paper has demonstrated that the artificial neural network can be applied to determine the relationships between inputs (i.e. $\mathrm{pH}$, collector, frother and $\mathrm{F}$-Oil concentration, size percentage of feed passing 75 microns, moisture content, solid percentage, grade of Copper, Molybdenum, and Iron in feed) and outputs (i.e. Copper, and Molybdenum grades and their recoveries).

2) Feed forward ANN with 10-10-10-4 structure is capable of predicting copper and molybdenum grades and their recoveries, simultaneously. The optimum structure is determined by the trial and error procedure.

3) In the testing stage, the used model could estimate copper and molybdenum grades and their recoveries, satisfactorily. The correlation coefficient $(\mathrm{R})$ values for testing sets were 0.93, 0.92 and $0.92,0.94$ in copper, molybdenum grades and their recoveries predictions, respectively, the results of which were quite satisfactory.

4) The proposed method can be applied as an expert system in copper flotation to evaluate the operational conditions for the expected grade and recovery without spending extra time and cost.

\section{Acknowledgements}

The authors would like to thank the Sarcheshmeh Copper Concentration Plant for supporting this research.

\section{References}

[1] Wills, B.A. and Napier-Munn, T. (2005) Mineral Processing Technology. Elsevier Ltd..

[2] Lee, Y., Oh, S.H. and Kim, M.W. (1991) The Effect of Initial Weights on Premature Saturation in Back-Propagation Learning. Proceedings of the International Joint Conference on Neural Networks (IJCNN’91), Seattle, 8-14 July 1991, 765-770. http://dx.doi.org/10.1109/IJCNN.1991.155275

[3] Kamran Haghighi, H., Moradkhani, D. and Salarirad, M.M. (2014) Modeling of Synergetic Effect of LIX 984N and D2EHPA on Separation of Iron and Zinc Using Artificial Neural Network. Transactions of the Indian Institute of Metals, 67, 331-341. http://dx.doi.org/10.1007/s12666-013-0354-7

[4] Acharya, C., Mohanty, S., Sukla, L.B. and Misra, V.N. (2006) Prediction of Sulphur Removal with Acidithiobacillus sp. Using Artificial Neural Networks. Ecological Modelling, 190, 223-230. http://dx.doi.org/10.1016/j.ecolmodel.2005.02.021 
[5] Jorjani, E., Chelgani, S.C. and Mesroghli, Sh. (2007) Prediction of Microbial Desulfurization of Coal Using Artificial Neural Networks. Minerals Engineering, 20, 1285-1292. http://dx.doi.org/10.1016/j.mineng.2007.07.003

[6] Jorjani, E., Chelgani, S.C. and Mesroghli, Sh. (2008) Application of Artificial Neural Networks to Predict Chemical Desulfurization of Tabas Coal. Fuel, 87, 2727-2734. http://dx.doi.org/10.1016/j.fuel.2008.01.029

[7] Fausett, L. (1994) Fundamentals of Neural Network. Prentice Hall, Hoboken.

[8] Hornik, K., Stinchcombe, M. and White, H. (1989) Multilayer Feed forward Networks Are Universal Approximators. Neural Networks, 2, 359-366. http://dx.doi.org/10.1016/0893-6080(89)90020-8

[9] Poggio, T. and Girosi, F. (1990) Regularization Algorithms for Learning that Are Equivalent to Multilayer Networks. Science, 247, 978-982. http://dx.doi.org/10.1126/science.247.4945.978

[10] Montana, D.J. and Davis, L. (1989) Training Feedforward Neural Networks Using Genetic Algorithms. Proceedings of the 11th international joint conference on Artificial Intelligence, Detroit, 20-26 August 1989, Vol. 1, 762-767.

[11] Labidi, J., Pelach, M.A., Turon, X. and Mutje, P. (2007) Predicting Flotation Efficiency Using Neural Networks. Chemical Engineering and Processing: Process Intensification, 46, 314-322. http://dx.doi.org/10.1016/j.cep.2006.06.011

[12] Mohanty, S. (2009) Artificial Neural Network Based System Identification and Model Predictive Control of a Flotation Column. Journal of Process Control, 19, 991-999. http://dx.doi.org/10.1016/j.jprocont.2009.01.001

[13] Cilek, E.C. (2002) Application of Neural Networks to Predict Locked Cycle Flotation Test Results. Minerals Engineering, 15, 1095-1104. http://dx.doi.org/10.1016/S0892-6875(02)00259-5

[14] Moolman, D.W., Aldrich, C. and Van Deventer, J.S.J. (1995) The Interpretation of Flotation Froth Surfaces by Using Digital Image Analysis and Neural Networks. Chemical Engineering Science, 50, 3501-3513. http://dx.doi.org/10.1016/0009-2509(95)00190-G

[15] Massinaei, M. and Doostmohammadi, R. (2010) Modeling of Bubble Surface Area Flux in an Industrial Rougher Column Using Artificial Neural Network and Statistical Techniques. Minerals Engineering, 23, 83-90. http://dx.doi.org/10.1016/j.mineng.2009.10.005

[16] Jorjani, E., Chehreh Chelgani, S. and Mesroghli, S. (2008) Prediction of Operational Parameters Effect on Coal Flotation Using Artificial Neural Network. Journal of University of Science and Technology Beijing, 15, 528-533. http://dx.doi.org/10.1016/S1005-8850(08)60099-7

[17] Banisi, S., Sarvi, M., Hamidi, D. and Fazeli, A. (2003) Flotation Circuit Improvements at the Sarcheshmeh Copper Mine. Mineral Processing and Extractive Metallurgy: Transactions of the Institution of Mining and Metallurgy: Section C, 112, 198-205. http://dx.doi.org/10.1179/037195503225003681

[18] Banisi, S. and Finch, J.A. (2001) Testing a Flotation Column at the Sarcheshmeh Copper Mine. Minerals Engineering, 14, 785-789. http://dx.doi.org/10.1016/S0892-6875(01)00073-5

[19] Haykin, S. (1999) Neural Networks: A Comprehensive Foundation. Prentice Hall, Upper Saddle River.

[20] Afkhami, A., Abbasi-Tarighat, M. and Bahrami, M. (2008) Artificial Neural Networks for Determination of Enantiomeric Composition of $\alpha$-Phenylglycine Using UV Spectra of Cyclodextrin Host-Guest Complexes: Comparison of Feed-Forward and Radial Basis Function Networks. Talanta, 75, 91-98. http://dx.doi.org/10.1016/j.talanta.2007.10.040

[21] Demuth, H. and Beale, M. (2002) Neural Network Toolbox for Use with MATLAB.

[22] Statsoft (1998) Statistica Neural Network. Statsoft, Tulsa. 


\section{Submit or recommend next manuscript to SCIRP and we will provide best service for you:}

Accepting pre-submission inquiries through Email, Facebook, LinkedIn, Twitter, etc.

A wide selection of journals (inclusive of 9 subjects, more than 200 journals)

Providing 24-hour high-quality service

User-friendly online submission system

Fair and swift peer-review system

Efficient typesetting and proofreading procedure

Display of the result of downloads and visits, as well as the number of cited articles

Maximum dissemination of your research work

Submit your manuscript at: http://papersubmission.scirp.org/ 